\title{
Diversity of Soil Bacterial Community Is Influenced by Spatial Location and Time but Not Potato Cultivar
}

\author{
Kamrun Nahar, ${ }^{1}$ Jean-Baptiste Floc' $h,{ }^{2}$ Claudia Goyer, ${ }^{1, \dagger}$ Bernie J. Zebarth, ${ }^{1}$ and Sean Whitney ${ }^{1}$ \\ ${ }^{1}$ Fredericton Research and Development Centre, Agriculture and Agri-Food Canada, 850 Lincoln Road, Fredericton, NB, E3B 4Z7 Canada \\ ${ }^{2}$ Institut de Recherche en Biologie Végétale, 4101 Rue Sherbrooke E, Montréal, QC H1X 2B2
}

Accepted for publication 2 April 2020.

\section{ABSTRACT}

Potato cultivars susceptible to common scab were previously reported to harbor five to six times more abundant pathogenic Streptomyces spp. in the rhizosphere soils compared with tolerant cultivars. It is still unclear if the diversity of soil bacterial communities is related to the abundance of pathogenic Streptomyces spp. This study evaluated the effects of potato cultivar on the diversity of bacterial communities in three spatial locations (soil located close to the plant [SCP], in the rhizosphere soil [RS], and in the geocaulosphere soil [GS]) in 2013 and 2014. Common scab tolerant (Goldrush and Hindenburg) and susceptible cultivars (Green Mountain and Agria) were planted in a field infested with pathogenic Streptomyces spp. causing common scab. The $\beta$-diversity of the bacterial community was significantly different between years and on dates within each year according to a permutational multivariate analysis of variance. The $\beta$-diversity also varied significantly among spatial locations (i.e., SCP, RS, and GS), probably due to changes in soil properties, but did not change significantly among potato cultivars. The architecture of the bacterial network in RS in 2014 was more complex compared with 2013 with a 2.5-fold increase in the number of bacteria included according to a co-occurrence analysis. These results indicated that the soil bacterial community diversity changed temporally and spatially. However, bacterial community diversity and richness were not affected by potato cultivar, suggesting that there were no relationships between bacterial community diversity or richness and the abundance of pathogenic Streptomyces spp.

Keywords: bacterial community diversity, common scab, cooccurrence network analysis, metagenomics, microbiome, soil ecology, Solanum tuberosum
Soil bacterial communities influence plant growth and health through nutrient mobilization, production of plant growth hormones, and induction of systemic resistance in the host plant (Raaijmakers et al. 2009; van der Heijden et al. 2008). In turn, soil bacterial communities benefit from nutrients provided by the plant root exudates, and consequently, their abundance and community composition are differentially influenced by plant species and, in some cases, by the plant cultivar (Gschwendtner et al. 2010; Hannula et al. 2012; Rasche et al. 2006). The rhizosphere is considered a "hot-spot" for bacterial abundance and metabolic activity due to the nutrients released by plant roots (Kuzyakov and Blagodatskaya 2015; Raaijmakers et al. 2009), which can result in

${ }^{\dagger}$ Corresponding author: C. Goyer; claudia.goyer@ canada.ca

Funding: This study was funded by the Agri-Innovation Program of Agriculture and Agri-Food Canada.

*The $\boldsymbol{e}$-Xtra logo stands for "electronic extra" and indicates that two supplementary figures are published online.

The author(s) declare no conflict of interest.

(C) Her Majesty the Queen in Right of Canada, as represented by the Minister of Agriculture and Agri-Food Canada, 2020. differences in diversity of bacterial communities between the rhizosphere and bulk soil (Yang et al. 2017).

Several factors are known to influence the diversity of soil bacterial communities in rhizosphere soils including soil type (Garbeva et al. 2006; Zhang et al. 2017), agricultural management practices (Griffiths et al. 2007; Verbruggen et al. 2010), and plant stress response due to pathogens (Yang et al. 2001). The plant growth stage affects the quality and quantity of root exudates which may result in selective pressure on root-associated bacterial communities at different growth stages (Gschwendtner et al. 2010; Pfeiffer et al. 2017). In potato, several studies have reported that the effect of potato cultivar on the diversity of bacterial communities depends on plant growth stages and/or soil properties (İnceoğlu et al. 2010; van Overbeek and van Elsas 2008; Weinert et al. 2009, 2010). Ínceoğlu et al. (2010) demonstrated that profiles of PCRdenaturing gradient gel electrophoresis (DDGE) of bacterial communities from the rhizosphere soil during the flowering period were similar for three potato cultivars but different from three other cultivars and that the clustering was different over time and between two different field sites.

It is well known that potato cultivars vary in their resistance/ tolerance or susceptibility to diseases (Stevenson et al. 2001) including common scab, a disease caused by several pathogenic 
Streptomyces spp. (Loria et al. 2006). A greater abundance of pathogenic Streptomyces spp. was observed in susceptible cultivars compared with tolerant cultivars in the tuber endosphere (Kopecky et al. 2018) or rhizosphere and geocaulosphere (tuber surface) soils (Nahar et al. 2018). Differences in composition and abundance of root exudates among potato cultivars could directly influence the growth of pathogenic Streptomyces spp. Alternatively, the root exudates may change the soil diversity of bacterial communities thus possibly selecting for antagonistic bacteria that decrease pathogenic Streptomyces spp. abundance. The effect of potato cultivar resistance to common scab on the abundance of pathogenic Streptomyces spp. and soil bacterial community diversity was evaluated in rhizosphere soils, root and/or tubers (Kopecky et al. 2018; Kobayashi et al. 2015). Soil bacterial community diversity from tuber surface soil was shown to be different between a resistant and a susceptible potato cultivar (Kopecky et al. 2018; Shi et al. 2019), or to be similar in the roots and tubers of four resistant and susceptible potato cultivars (Kobayashi et al. 2015), and thus a possible relationship between changes in the diversity of bacterial communities and the abundance of pathogenic Streptomyces spp. mediated by potato cultivars is still poorly understood.

Although some information on the diversity of bacterial communities of the potato rhizosphere is available, only one study has evaluated the network of co-occurrence of the bacterial communities in the rhizosphere of potato (Pfeiffer et al. 2017). The core microbiome of the rhizosphere of a potato cultivar, grown at three sites in the Andes, was different at emergence compared with flowering and senescence growth stages based on a network cooccurrence analysis (Pfeiffer et al. 2017); however, the specific coassociations or covariances between bacterial species in the potato rhizosphere have not yet been explored.

The objective of this study was to investigate the effect of potato cultivar, including two tolerant (Goldrush and Hindenburg) and two susceptible (Green Mountain and Agria) cultivars, on the diversity of bacterial communities in three spatial locations (soil close to the plant [SCP, i.e., bulk soil], rhizosphere soil [RS], and geocaulosphere soil [GS]) in 2013 and 2014. The hypotheses were that (i) bacterial community diversity varies with potato cultivar, spatial location (i.e., SCP, RS, and, GS) and over time within a growing season; (ii) bacterial community composition and architecture of bacterial networks vary due to changes in soil properties and environmental conditions between years; and (iii) bacterial $\alpha$ - and/or $\beta$-diversity are different between tolerant and susceptible potato cultivars which may be associated with the lower abundance of the pathogenic Streptomyces spp. in tolerant potato cultivars. This study used the same soil samples as a previous study that evaluated the effect of potato cultivars on the abundance of pathogenic Streptomyces spp. (Nahar et al. 2018).

\section{MATERIALS AND METHODS}

Experimental site and treatments. The field trials were conducted at the Fredericton Research and Development Centre of Agriculture and Agri-Food Canada (Fredericton, NB, Canada; latitude $45^{\circ} 55^{\prime} 13.000^{\prime \prime} \mathrm{N}$, longitude $66^{\circ} 36^{\prime} 32.010^{\prime \prime} \mathrm{W}$, World Meteorological Organization ID: 71668) in a field naturally containing pathogenic Streptomyces spp. causing common scab. The field was under continuous potato crop production since 2001. The experiments were conducted from May to September of 2013 and 2014, as Nahar et al. (2018) previously described. The trials were established on 6 June 2013 and 28 May 2014 at nearby locations within the same field site. Each trial used a randomized complete block design with four treatments and four blocks. The treatments consisted of four potato cultivars including two common scab tolerant cultivars (Goldrush and Hindenburg) and two susceptible cultivars (Green Mountain and Agria). Each block consisted of eight rows of $30 \mathrm{~m}$ (2013) or $19 \mathrm{~m}$ (2014). The susceptible cultivar Shepody was used as a space-filler in the blocks and as guard rows. Plots were randomly located in each block where a plot consisted of 20 potato plants of a given cultivar planted as a row. The cultivars were separated by five plants of a red variety (Chieftain) to avoid mixing between cultivars at harvest. Granular fertilizer (formulation 17-17-17 of N-P-K) was banded at the time of planting with a rate of $1,134 \mathrm{~kg} \mathrm{ha}^{-1}$. Standard practices for commercial agriculture were used for control of diseases, insects, and weeds (Bernard et al. 1993). No irrigation was applied as is standard practice in this region.

Soil sampling, measurements of soil physicochemical properties, and environmental conditions. Soil samples were collected from three spatial locations: (i) soil close to the plant (i.e., bulk soil sampled from the hill adjacent to the plant; SCP); (ii) rhizosphere soil (i.e., the soil in close contact with roots; RS); and (iii) geocaulosphere soil (i.e., the soil in close contact with potato tubers; GS). Soils were sampled at two plant growth stages: at late tuberization stage (1 August 2013 and 28 July 2014) and at tuber bulking stage (28 August 2013 and 2014). One plant per plot was randomly selected on each sampling date. Plants and soil surrounding the roots were gently removed using a shovel. The SCP was obtained by shaking the soil surrounding the roots in a large plastic bag, mixing, and then collecting a subsample in a sterile $15 \mathrm{ml}$ tube. After shaking off and discarding any loose soil from the roots and tubers, RS and GS were sampled by collecting the first few millimeters of adhering soil from the roots and tubers by gently scraping the roots and tubers with clean gloves and the top edge of the sterile $15-\mathrm{ml}$ collection tubes. Soil samples were frozen immediately after collection using liquid nitrogen and subsequently stored at $-80^{\circ} \mathrm{C}$ until lyophilized using a Labconco FreeZone 6 freeze dryer. Freeze drying started at $-40^{\circ} \mathrm{C}$ and the temperature increased to $10^{\circ} \mathrm{C}$ over $72 \mathrm{~h}$. Soils were stored at $-80^{\circ} \mathrm{C}$ until processed. Delayed planting and plant growth in summer 2013 resulted in very small tubers thus eight soil samples could not be collected due to insufficient soils being available.

Soil (5 g) was extracted with $0.5 \mathrm{M} \mathrm{K}_{2} \mathrm{SO}_{4}$ (1:2 soil/extractant ratio), filtered, and stored at $-20^{\circ} \mathrm{C}$ pending analysis. Blank solution samples were also filtered to estimate contamination. Segmented flow analysis (Technicon Industrial Systems, Tarrytown, NY, U.S.A.) was used for the colorimetric measurement of extractable organic carbon (EOC), ammonium $\left(\mathrm{NH}_{4}^{+}-\mathrm{N}\right)$, and nitrate $\left(\mathrm{NO}_{3}^{-}-\mathrm{N}\right)$ concentrations (Miller et al. 2008). Soil pH was measured using a $\mathrm{pH}$ meter after shaking a soil/water (1:1) solution.

The soil bacterial communities would be most affected by the environmental conditions over the period of time closer to the sampling dates. For this reason, daily atmospheric minimum, maximum, mean temperatures and daily rainfall were averaged over 7 days prior to each individual sampling date in 2013 and 2014. Climate data were obtained from the Fredericton CDA weather station of Environment Canada (https://climate.weather.gc.ca/ historical_data/search_historic_data_e.html) located approximately $20 \mathrm{~m}$ from the experimental field site.

DNA extraction and quantification of pathogenic Streptomyces spp. using qPCR. Absolute quantification of populations of pathogenic Streptomyces spp. abundance was performed using TaqMan based quantitative PCR (qPCR) targeting the $t x t C$ gene as described in Nahar et al. (2018). The $t x t C$ gene encodes a cytochrome P450 monooxygenase involved in the biosynthesis of thaxtomins that are plant toxins important for the pathogenicity of Streptomyces spp. causing common scab. The forward primer (txtC-F:TGTTCGTGGACGACGGAGAACTT), the reverse 
primer (txtC-R: TACGACACGACGGCCAGCACCAT) and the probe (txtC-P: AGTGCATAACTCACCAAGGACAGCGA) were used (Nahar et al. 2018). Primers and TaqMan probes were purchased from Integrated DNA Technologies. The qPCR reactions were conducted using the TaqMan Fast Advanced Master Mix (Thermo Fisher Scientific, Toronto, Canada) and a Step One Plus Real-Time PCR System (Applied Biosystems, Streetsville, ON, Canada). Each 10- $\mu$ l reaction contained primers and probe (200 $\mathrm{nM}$ ) and $2 \mu \mathrm{l}$ of 1:10 diluted DNA (15 to $70 \mathrm{ng} / \mu \mathrm{l})$. Three qPCR replicates were used per sample and three no-template controls were included during each qPCR run. The thermal cycling conditions were as follows: $2 \mathrm{~min}$ at $50^{\circ} \mathrm{C}, 20 \mathrm{~s}$ at $95^{\circ} \mathrm{C}$, followed by 40 cycles of $1 \mathrm{~s}$ at $95^{\circ} \mathrm{C}$ and $20 \mathrm{~s}$ at $60^{\circ} \mathrm{C}$. Standard curves were generated using five replicates of serial dilutions of a known number of plasmids containing a 2,265-bp fragment of the $t x t C$ gene of pathogenic Streptomyces spp. The standard curve descriptors were as follows: slope $=-3.1$ to -3.3 , efficiency $(\mathrm{E})=100.0$ to $111.7 \%$, coefficient of determination $\left(R^{2}\right)=0.98$ to 0.99 , and intercept $(\mathrm{Y})=$ 35.8 to 40.6 .

16S rRNA gene PCR amplification, library preparation, and sequencing. The $16 \mathrm{~S}$ rRNA gene amplification was performed using the V4 region forward primer (515F: GTGCCAGCMG CCGCGGTAA) and reverse (806R: GGACTACHVGGGTWTC TAAT) that were fused to Illumina sequence adapters and dual-indexed primers (Schloss et al. 2009). The MiSeq Wet Lab Standard Operating Procedure (SOP) from Schloss et al. (2009) was used for library construction and sequencing. The PCR reaction was done using $17 \mu \mathrm{l}$ of Accuprime Pfx Supermix (Thermo Fisher Scientific, Waltham, USA), $1 \mu \mathrm{l}$ (1:10 diluted) template DNA of each sample, and $2 \mu \mathrm{l}$ of the paired set of dual-index primers for a total volume of $20 \mu \mathrm{l}$. Amplifications were performed on Mastercyler Nexus Thermal Cycler (Eppendorf, Hamburg, Germany) using the following program: $2 \mathrm{~min}$ at $95^{\circ} \mathrm{C} ; 30$ cycles of $95^{\circ} \mathrm{C}$ for $20 \mathrm{~s}, 55^{\circ} \mathrm{C}$ for $15 \mathrm{~s}$, and $72^{\circ} \mathrm{C}$ for $5 \mathrm{~min}$; and $72^{\circ} \mathrm{C}$ for $10 \mathrm{~min}$ (Schloss et al. 2009). PCR products were purified and normalized using SequalPrep Normalization Plate kit (Invitrogen, Carlsbad, CA, U.S.A.). The library quality was assessed on the Qubit 2.0 Fluorometer (Thermo Scientific) and Agilent Bioanalyzer 2100 system. The library was sequenced using the MiSeq v2 Reagent kit (500 cycles) (Illumina, San Diego, CA, U.S.A.) and the Illumina MiSeq platform. Paired-end reads of $250 \mathrm{bp}$ were generated according to the Schloss lab protocol ensuring a low sequencing error rate (Schloss et al. 2009; Wang et al. 2007). Demultiplexing was done automatically on the MiSeq to generate the read 1 and read 2 for all indexed samples. The raw sequence reads were deposited into the NCBI Sequence Read Archive database under accession numbers SAMN12621424 to SAMN12621607. The error rate during sequencing and data processing was evaluated using a bacterial mock community consisting of 24 bacterial species (BEI Resources, Manassas, VA, U.S.A.), which showed a probability of incorrect base calling of $2.55 \times 10^{-5}$ in this study.

Illumina MiSeq sequence data processing. The demultiplexed paired-end fastq sequence data were analyzed using mothur (Version 1.34.2) and MiSeq SOP (Schloss et al. 2009). Briefly, paired-end sequences were merged then sequences with ambiguous base calls, erroneous length $(<275 \mathrm{bp})$ or with $>8$ homopolymers were discarded. The sequence reads were simplified by the unique.seqs command and aligned with the SILVA reference aligned databases v. 128 (Quast et al. 2013; Yilmaz et al. 2014) using the Needleman-Wunsch global alignment method (Needleman and Wunsch 1970). The aligned sequences were clustered by the pre.cluster command (diffs option $=2$ ) and sequences were checked for chimera using UCHIME (Edgar et al. 2011) and chimeric sequences were removed. The sequences were clustered into operational taxonomic units (OTUs) with a sequence similarity of $97 \%$ (or at the $3 \%$ evolutionary distance) using the average neighbor algorithm. The taxonomic assignment of each OTU was performed by using mothur formatted version of the Ribosomal Database Project classifier training set (v. 16) from SILVA v.128 (Quast et al. 2013; Wang et al. 2007) at a confidence threshold of $80 \%$. Sequences that were unclassified or assigned to Eukaryota, Archaea, mitochondria, and chloroplast were removed. Rarefaction curves were generated based on the observed OTUs. The number of sequences was normalized across all samples to 9,949 reads using a random subsample method. Alpha-diversity was measured using the Shannon index (H') while richness was assessed using the Chao1. These two indices were calculated with mothur (version 1.34.1, Schloss et al. 2009).

Common scab disease severity. Twenty randomly selected tubers from each plot were harvested in the fall of 2013 and 2014 and used to evaluate disease severity. The tubers were washed and disease severity was evaluated visually on each tuber. Disease severity was measured by determining the percentage of the tuber surface covered by lesions (i.e., a score between 0 to 100\%) and comparing with a disease scoring key to help evaluate the extent of the symptoms and to ensure that the evaluation was consistent.

Statistical analysis. Analyses of variance were performed using Systat (version 13). The abundances of pathogenic Streptomyces spp. from (i) SCP and (ii) associated with the plant (RS+GS) were analyzed separately using the general linear model (GLM) based on a randomized complete block design with cultivars, sampling time and block as fixed factors for 2013 and 2014, individually. Two different approaches were used to analyze Shannon index ( $\left.H^{\prime}\right)$ and Chaol including GLM with (i) spatial locations, year and block as fixed factors and (ii) GLM with cultivars, time (within dates), and block as fixed factors. For properties of SCP, the analysis of variance was performed using time (within season dates) and block as fixed factor for 2013 and 2014 individually. Means were compared using Fisher's least significant difference test.

To evaluate the $\beta$-diversity of the bacterial community, data were square root transformed and Bray-Curtis similarities were generated. The $\beta$-diversity of the bacterial community was analyzed using a permutational multivariate analysis of variance (PERMANOVA) with cultivar, time, and spatial location using Primer6 software (Anderson et al. 2008). Differences in bacterial composition were evaluated (i) between years, (ii) between sampling dates of a given year, (iii) among spatial locations, and (iv) among cultivars, using nonmetric multidimensional scaling (nMDS) ordination generated using Primer6 software.

Differences in the relative abundance of the most abundant OTUs were determined among the four cultivars and three spatial locations using heat maps. The 20 most abundant OTUs were selected for each sampling date of 2013 and 2014. The relative abundance of OTUs was calculated as the number of sequences of a given OTU divided by the total number of sequences of the 20 selected OTUs and then averaged over the four replicates. Individual OTUs are presented (i.e., the species belonging to the same genus were not grouped in a single OTU) in order to better observe differences in relative abundance. The heat map option within the gplots package of RStudio ( $\mathrm{R}$ version 3.5.0) was used to create the heat maps.

The covariations among taxa of the bacterial community in RS were performed using results of the combined four cultivars for each year individually because it was previously shown that a high number of samples is required in order for the co-occurrence analysis to be meaningful (Kurtz et al. 2015). The networks of co-occurrence were determined using the SPIEC-EASI statistical method (package SpiecEasi v 1.0.6 in R 3.4.3). SPIEC-EASI relies 
on algorithms for sparse neighborhood and inverse covariance selection to construct the network (Kurtz et al. 2015). The input data consisted of the matrix of the raw abundance of OTUs in each year. The dataset was filtered to remove the OTUs with a frequency less than $20 \%$ across all samples. The algorithm "glasso" with the lambda min ratio set at $10^{-2}$ and 50 repetitions were used for the analyses. The networks were plotted using the Cytoscape software (version 3.7.0) with the organic layout. Edges were defined as cooccurrences or mutual exclusion using the positive or negative values of inverse covariance between nodes, respectively. Hub-taxa were defined as the nodes possessing a high score of betweenness centrality, a measure of the number of times a node acts as a bridge along the shortest path between two other nodes, of $>0.09$, and as having an important number of connections in the network. The identification of hub-taxa aims at identifying the OTUs that could be of ecological importance in the functioning of the potato rhizosphere. The consistent covariances between the hub-taxa or taxa with the highest connectivity scores and other taxa in both 2013 and 2014 were explored. The connectivity information was imported in Cytoscape using an R script, and the consistent covariances in 2013 and 2014 were visually identified.

\section{RESULTS}

Environmental conditions and soil properties. Planting in 2013 was delayed (6 June) compared with 2014 (28 May) because the environmental conditions were unfavorable. Differences in atmospheric temperatures and rainfall averaged over a 7-day period prior to each sampling date were observed between sampling dates of a given year and between years (Table 1). Minimum, maximum, and daily temperatures averaged over the 7 days prior to sampling were greater in 2014 compared with 2013 (Table 1). There was 2.7fold greater average daily rainfall in 2013 compared with 2014.

There were significant differences in soil properties within season and between years (Table 2). Soil pH was slightly, but significantly, greater in 2014 compared with 2013. Concentrations of soil mineral
$\mathrm{N}$ were generally low; however, $\mathrm{NH}_{4}^{+}$concentrations were 2.6-fold greater in 2014 compared with 2013, while $\mathrm{NO}_{3}^{-}$concentrations were greater in August 2014 compared with other sampling dates. EOC was not significantly different over all sampling dates.

Disease severity and abundance of pathogenic Streptomyces spp. There was significantly greater common scab disease severity in susceptible potato cultivars Agria and Green Mountain compared with tolerant cultivars Goldrush and Hindenburg in both 2013 and 2014 (Nahar et al. 2018). Surface lesion coverages were 15 and 10\% in 2013 and 20 and 19\% in 2014 in Agria and Green Mountain, respectively, while Goldrush and Hindenburg had a lesion coverage of $<2 \%$ in both years.

The abundance of pathogenic Streptomyces spp. was lower in SCP when averaged among cultivars and over the two sampling times compared with plant-associated soils $(\mathrm{RS}+\mathrm{GS})$ with $7.11 \times$ $10^{5}$ and $2.31 \times 10^{5}$ in SCP and $1.91 \times 10^{8}$ and $6.63 \times 10^{7}$ gene copy number $\mathrm{g}^{-1}$ of soil in plant-associated soils in 2013 and 2014, respectively (Fig. 1). The time-cultivar interaction was not significant in SCP and plant-associated soils. There were no significant differences in the abundance of pathogenic Streptomyces spp. in SCP in 2013 (Fig. 1A); however, the common scab susceptible cultivars, Agria and Green Mountain, had a greater abundance of pathogenic Streptomyces spp. compared with tolerant cultivars, Goldrush and Hindenburg, in SCP in 2014 (Fig. 1C). In both 2013 and 2014, there was a greater abundance of pathogenic Streptomyces spp. in plant-associated soils for Agria and Green Mountain compared with Goldrush and Hindenburg, but no differences between the two susceptible cultivars or between the two tolerant cultivars were observed. There was a significantly greater abundance of pathogenic Streptomyces spp. in plant-associated soils on 28 August 2013 and 2014 compared with 1 August 2013 or 28 July 2014 with 100- and 7-fold increases, respectively.

Sequencing information. In total, 6,392,302 high-quality sequences were obtained from the 184 soil samples. The rarefaction curves were close to reaching a plateau, indicating that most of the community diversity was sequenced (Supplementary Fig. S1). There

TABLE 1

Environmental conditions averaged over the 7-day-period prior to each sampling date in 2013 and 2014

\begin{tabular}{lcccc}
\hline & \multicolumn{2}{c}{2013} & & 2014 \\
\cline { 2 - 4 } Parameters & 25 Jul. to 1 Aug. & 21 to 28 Aug. & 21 to 28 Jul. & 21 to 28 Aug. \\
\hline 7-day maximum temperature $\left({ }^{\circ} \mathrm{C}\right)$ & 23.2 & 26.0 & 26.9 & 26.1 \\
\hline 7-day minimum temperature $\left({ }^{\circ} \mathrm{C}\right)$ & 13.5 & 13.0 & 14.0 & 20.5 \\
\hline 7-day mean temperature $\left({ }^{\circ} \mathrm{C}\right)$ & 18.4 & 19.4 & 5.3 & 19.9 \\
\hline 7-day daily precipitation $(\mathrm{mm})$ & 14.5 & 3.5 & 1.28 \\
\hline
\end{tabular}

TABLE 2

Soil properties in bulk soil close to the plant in 2013 and $2014^{z}$

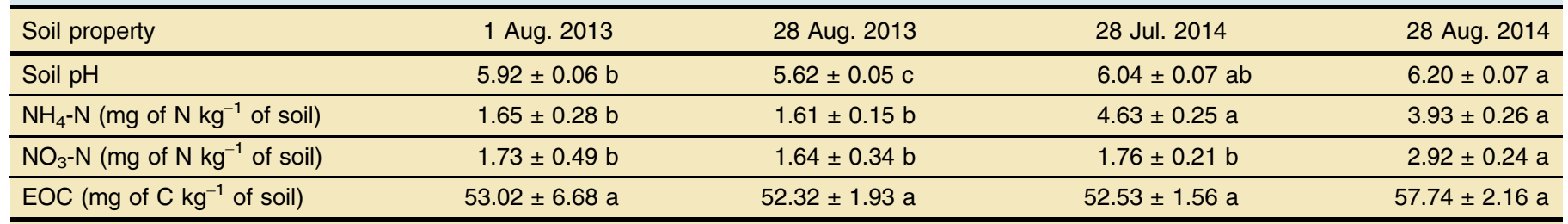

z EOC, extractable organic carbon; $\mathrm{NH}_{4}^{+}-\mathrm{N}$, ammonium; and $\mathrm{NO}_{3}^{-}-\mathrm{N}$, nitrate. Means and standard errors are presented. Data were analyzed using analysis of variance and least significant difference tests. Mean values in the same row followed with the same letter are not significantly different $(P \leq 0.05)$. 
were 26,862 distinct OTUs using a threshold of 3\% dissimilarity among all soil samples. In 2013 and 2014, 21,907 and 21,228 OTUs were observed, respectively. Single sequences (singletons) represented $23 \%$ of the OTUs. The cut-off for sequence good coverage was $89 \%$.

Changes in $\alpha$ - and $\beta$-diversity of bacterial communities between dates and years and among cultivars and spatial locations. The bacterial richness (Chao1) and $\alpha$-diversity (Shannon index [H']) were compared over spatial locations in 2013 and 2014 (Fig. 2A and B). Bacterial richness was significantly greater in all spatial locations (SCP, RS, and GS) in 2013 compared with 2014 (Fig. 2A). Similarly, the $\alpha$-diversity of the bacterial community was significantly greater in 2013 compared with 2014, except for SCP in 2014 (Fig. 2B).
The richness and $\alpha$-diversity of bacterial communities were compared among cultivars and between sampling dates for each spatial location (SCP, RS, and GS) and each year (2013 and 2014). There were no significant cultivar-time interactions in the richness of the bacterial community in SCP, RS, or GS in 2013 (Fig. 3A, C, and E). However, Goldrush had a significantly greater richness compared with other cultivars in SCP in 2013 when averaged over time (Fig. $3 \mathrm{~A})$. No significant differences in the bacterial community richness among cultivars were observed in SCP and RS on 28 July 2014; however, Agria had a greater bacterial community richness compared with other cultivars in SCP or to Goldrush but not to other cultivars in RS on 28 August 2014 (Fig. 3B and D). There was no significant cultivar-time interaction in the richness of the bacterial community in the GS in 2014 (Fig. 3F). However, the common scab-resistant Goldrush and Hindenburg had a significantly greater bacterial
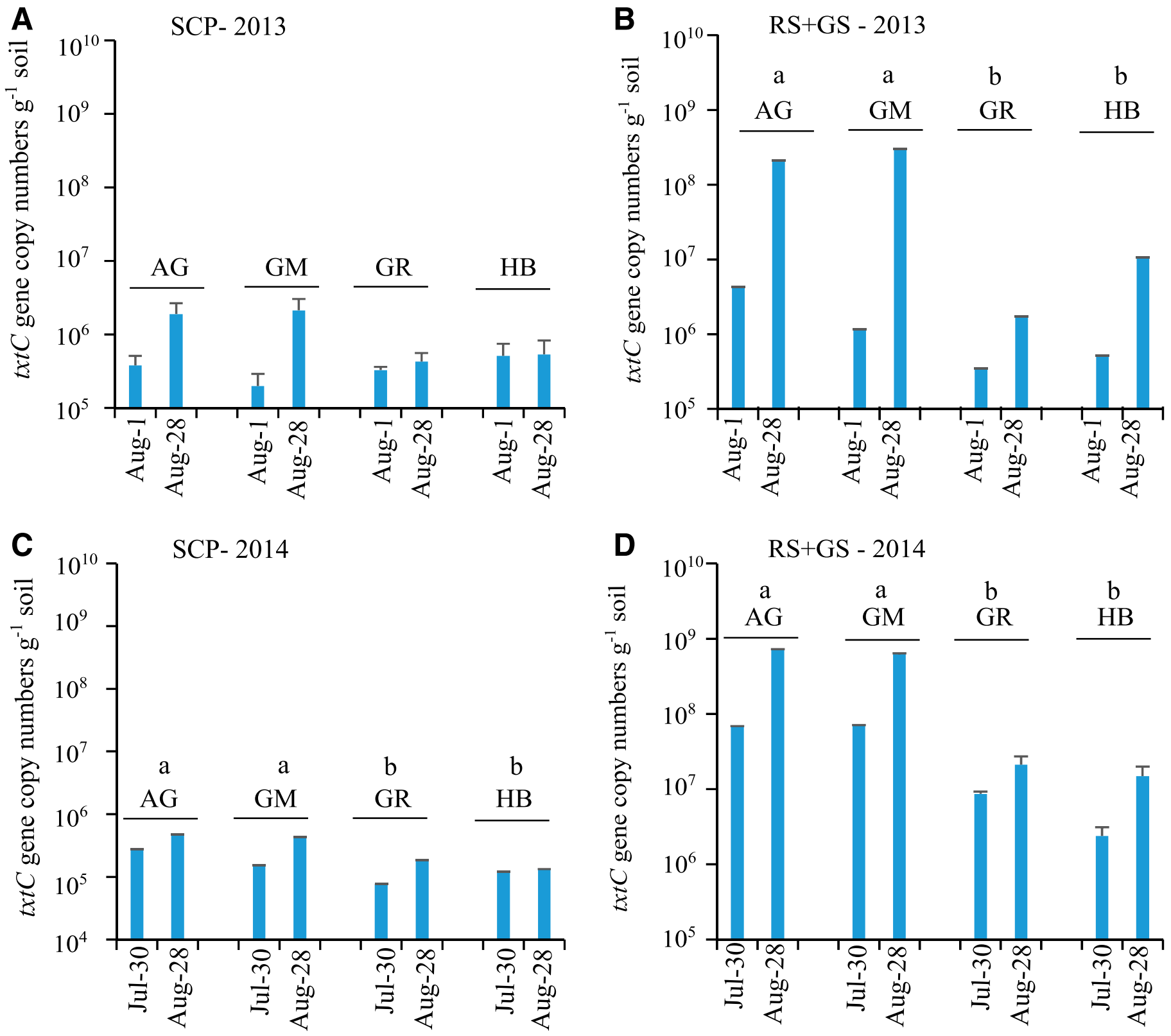

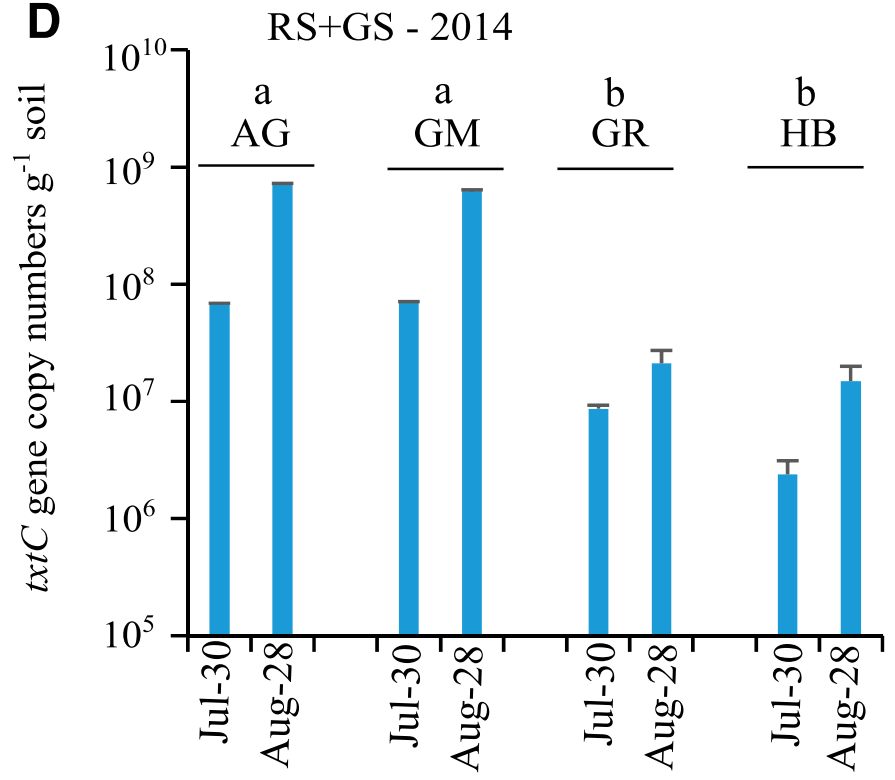

Fig. 1. Abundance of pathogenic Streptomyces spp. in soil close to the plant (SCP) and in soil associated with the plant (rhizosphere soil [RS] and geocaulosphere soils [GS]) in A and B, 2013 and C and D, 2014. The abundance of pathogenic Streptomyces spp. was measured using quantitative PCR targeting the $t x t C$ gene. Values followed with the same letter are not significantly different $(P \leq 0.05)$. Statistical results were added only if significant differences were observed. 
community richness compared with the susceptible cultivars Agria and Green Mountain in the GS when averaged over time (Fig. 3F).

No significant cultivar-time interaction in the $\alpha$-diversity of the bacterial community in the SCP and RS was observed in 2013 (Fig. 4A and C). Agria and Green Mountain had significantly lower $\alpha$-diversity of the bacterial community compared with Goldrush and Hindenburg in GS on 28 August 2013, but no differences were observed on 1 August 2013 (Fig. 4E). The $\alpha$-diversity of the bacterial community of Agria was greater compared with Goldrush in SCP on 28 August 2014 but no other differences were observed among cultivars on either date (Fig. 4B). The time-cultivar interactions for the $\alpha$-diversity of the bacterial community in RS and GS were not significant in 2014 (Fig. 4B and D). However, the $\alpha$-diversity of bacterial community was lower for Goldrush compared with other cultivars in GS in 2014 when averaged over time (Fig. 4F).

There was a significant location-time interaction on the $\beta$ diversity of the bacterial community in 2013 but not in 2014 according to a PERMANOVA (Table 3). Significant differences in the $\beta$-diversity of the bacterial community were observed among spatial locations and sampling dates in 2013 and 2014. The $\beta$-diversity of the bacterial community varied significantly between sampling dates in both years according to the PERMANOVA $(P<$ 0.001 ) and nMDS (Fig. 5A and B). The $\beta$-diversity of the bacterial community was significantly different among the three spatial
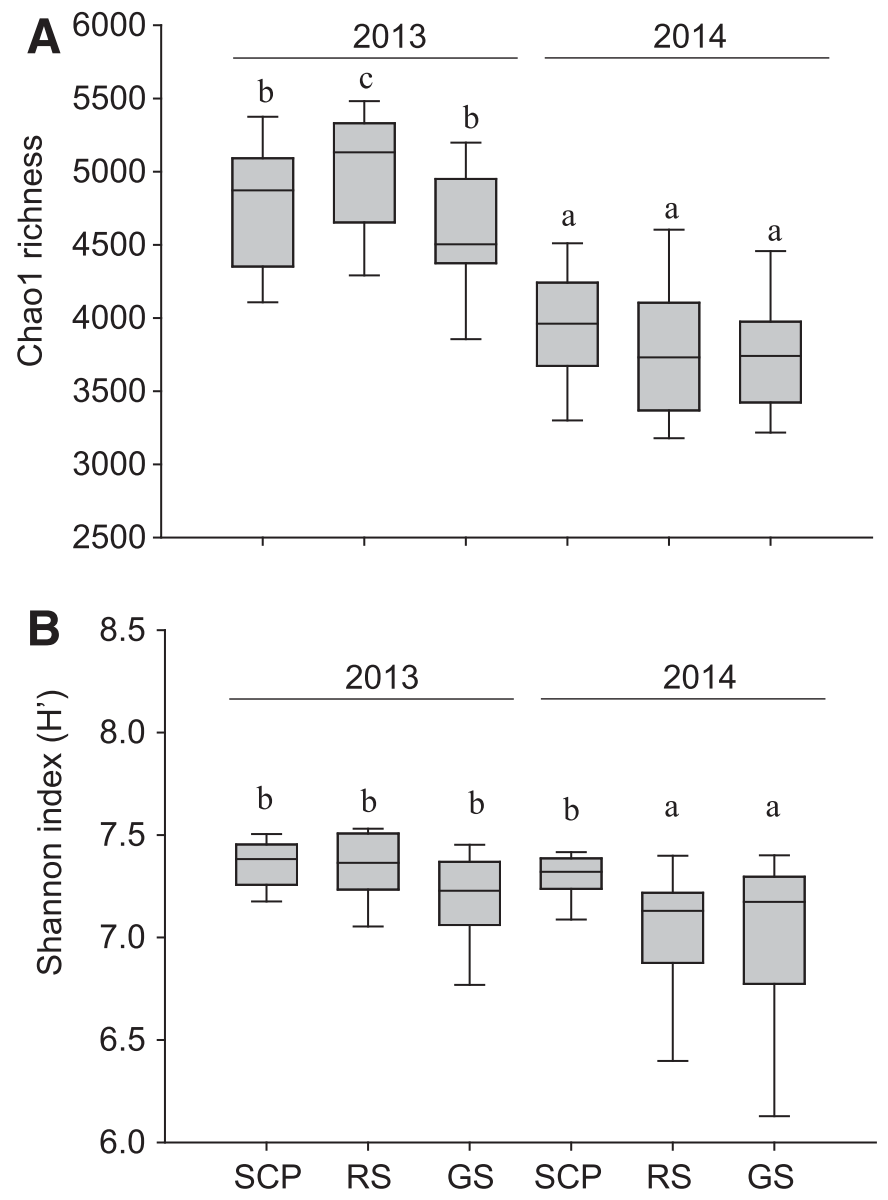

Fig. 2. Comparison of bacterial community $\alpha$-diversity in each spatial location (SCP, soil close to the plant; RS, rhizosphere; and GS, geocaulosphere soils) for 2013 and 2014. Box and whisker plots showing A, Chao1 richness and B, Shannon's diversity index ( $\left.H^{\prime}\right)$ for 2013 and 2014. Values followed with the same letter are not significantly different $(P \leq 0.05)$. locations (SCP, RS, and GS) in 2013 and 2014 as indicated by the nMDS (Fig. 5C and D). However, there were no significant differences in the $\beta$-diversity of the bacterial community among cultivars in 2013 and 2014 according to PERMANOVA and nMDS (Table 3, Fig. 5E and F).

Relative abundance of the $\mathbf{2 0}$ more abundant OTUs among cultivars and locations. The relative abundances of seven OTUs (Streptomyces [OTU1], Bradyrhizobium [OTU2], Acidobacteria subgroup 6 [OTU3, OTU5, and OTU8], Pseudoarthrobacter [OTU4], and Gemmatimonadaceae [OTU10]) were consistently among the 20 most abundant OTUs on both sampling dates in 2013 and 2014 (Fig. 6). Pseudolabrys (OTU14) and Acidobacteria subgroup 6 (OTU21) were among the 20 most abundant OTUs in all dates and years except 28 August 2014. Chloroflexi KD4-96 (OTU18) was among the 20 most abundant OTUs on the first sampling date of 2013 and 2014 but not the second sampling date of 2013 and 2014. In contrast, Verrucomicrobia OPB35 (OTU27) and Flavobacterium (OTU31) were among the most abundant OTUs on 28 August 2013 and 2014 but not on 1 August 2013 and 28 July 2014.

The spatial location had an effect on the relative abundances of the OTUs (Fig. 6). For example, the relative abundances of Rhodanobacter (OTU87) on 1 August 2013 and Acidobacteria subgroup 6 (OTU21) on 28 August 2013 were greater for the SCP among three or four of the cultivars compared with RS and GS. The relative abundances of Devosia (OTU22), Pseudomonas (OTU9), and Flavobacterium (OTU13) among all cultivars were greater in the RS and GS compared with the SCP on 28 July and 28 August
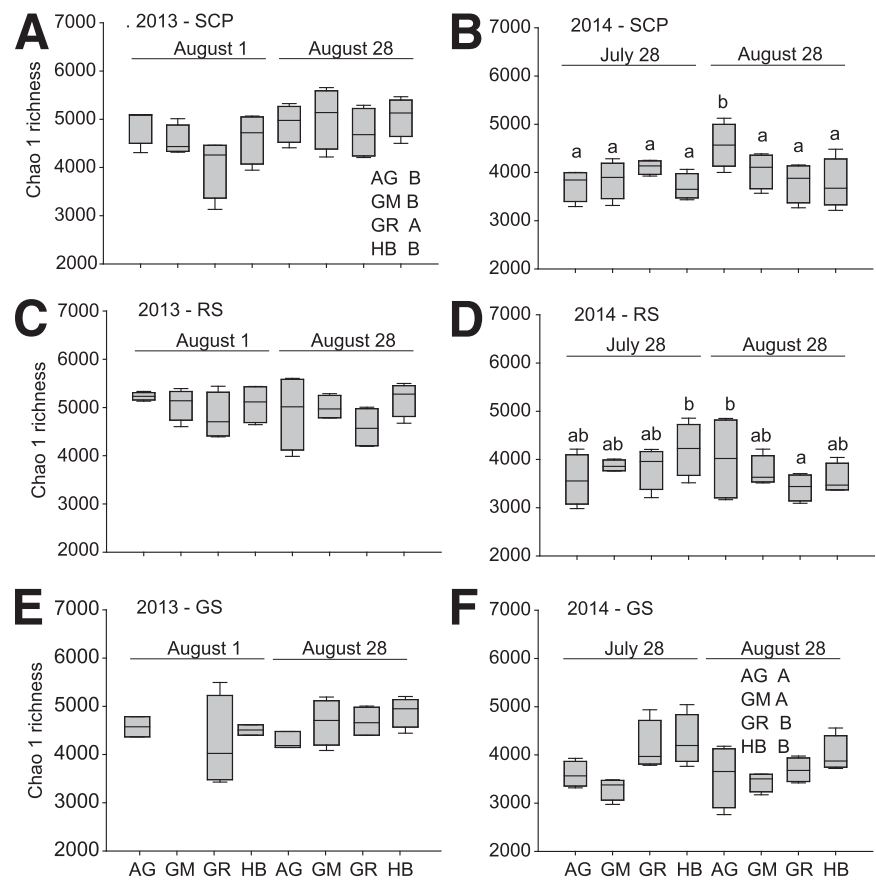

Fig. 3. Richness (Chao1) of bacterial community of four potato cultivars (Agria, AG; Green Mountain, GM; Goldrush, GR; and Hindenburg, HB) in three spatial locations including $\mathbf{A}$ and $\mathbf{B}$, soil close to the plant (SCP), $C$ and $D$, rhizosphere (RS), and $E$ and $F$, geocaulosphere (GS) on two sampling dates in 2013 and 2014. Data for the geocaulosphere soils of Green Mountain for 1 August 2013 is not available due to poor tuberization. Significant differences among mean values are represented in two ways $(P<0.05)$ : (i) differences among treatment means for individual cultivars are represented by letters above the boxes, (ii) differences among treatment means averaged across time points are shown by capital letters beside the cultivar names. Statistical results were presented only if significant differences were observed. 
2014. A consistently lower or greater relative abundance among all cultivars was not observed in GS in 2013 or 2014.

Differences in relative abundance of OTUs between common scab susceptible and resistant cultivars were observed in the RS and GS. For example, the RS of susceptible cultivars had greater relative abundances of Chloroflexi KD4-96 (OTU19) on 1 August 2013 (Fig. 6A) and Pseudomonas (OTU23) on 28 August 2014 (Fig. 5D) compared with tolerant cultivars. In contrast, the RS of tolerant cultivars had greater relative abundances of Acidobacteria subgroup 6 (OTU21) on 28 August 2013 and Devosia (OTU22) on 28 July 2014 compared with susceptible cultivars (Fig. 6B and D). The relative abundance of Streptomyces (OTU1) in the GS was greater in the susceptible cultivars on 28 August 2013, 28 July 2014, and 28 August 2014. In contrast, the relative abundance of Bradyrhizobium (OTU02) (1 August 2013 and 28 August 2014) and Sphingomonas (OTU11) (1 August 2013 and 28 July 2014) was greater in tolerant cultivars compared with susceptible cultivars in the GS.

Networks of bacterial co-occurrences in 2013 and 2014. Networks of bacterial co-occurrences in the RS of all cultivars combined were evaluated for both 2013 and 2014. In 2013, the network had 245 nodes and 1,375 edges (potential covariations) (Fig. 7A). Out of the 1,375 edges, 840 edges were positive cooccurrences while 535 were negative co-occurrences. In 2014, the architecture of the bacterial network was more complex with a 2.5-
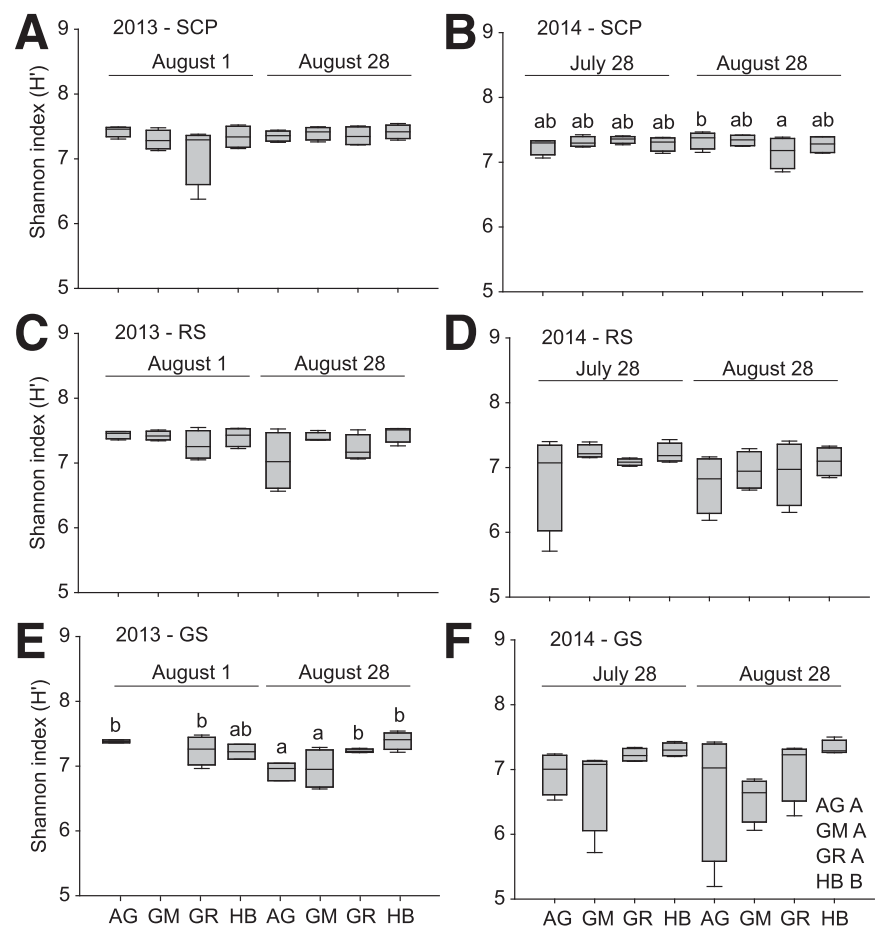

Fig. 4. Bacterial community $\alpha$-diversity as measured by Shannon index $\left(H^{\prime}\right)$ of four potato cultivars (Agria, AG; Green Mountain, GM; Goldrush, GR; and Hindenburg, HB) in three spatial locations including $\mathbf{A}$ and $\mathbf{B}$, soil close to the plant (SCP), C and D, rhizosphere soil (RS), and $E$ and $F$, geocaulosphere soil (GS) on two sampling dates in 2013 and 2014. Data for the geocaulosphere soils of Green Mountain is not available for 1 August 2013 due to poor tuberization. Significant differences among mean values are represented in two ways $(P<0.05)$ : (i) differences among treatment means for individual cultivars are represented by letters above the boxes and (ii) differences among treatment means averaged across time points are shown by capital letters beside the cultivar names. Statistical results were presented only if significant differences were observed. fold increase in the number of bacterial OTUs included in the network compared with 2013 (Fig. 7B). The bacterial network of 2014 consisted of 603 nodes and 6,248 edges of which 2,332 were positive and 3,916 were negative co-occurrences. There was no taxonomical structure detected in the networks since the taxonomically related OTUs were not grouped.

Acidobacteria subgroup 6 (OTU55) was identified as a hub-taxa in 2013 sharing 54 potential covariances with other OTUs, making this OTU the most connected of the network (Fig. 7A). This OTU had a score of betweenness centrality of 0.097 . The average betweenness centrality score of the OTUs was 0.009 in 2013; however, in 2014 it was 0.003 , indicating an increase in the network complexity and a decrease of the influence of single nodes on network architecture in 2014. Pseudolabrys (OTU14) and Acidobacteria subgroup 6 (OTU21) were the two OTUs with the highest connectivity scores with 90 and 61 connections, respectively (Fig. 7B). The scores of betweenness centrality of OTU14 and OTU21 were low in 2014 with 0.033 and 0.030 , respectively, indicating that their presence did not significantly change the network architecture; however, these OTUs should still be considered important given their high number of potential covariations. In 2013 and 2014, there were two positive covariances between OTU14 and OTU10 or OTU191 and a negative covariance between OTU14 and OTU204.

Among all covariances observed, 15, 3, and 20\% of the covariances observed between hub-taxa (Acidobacteria subgroup 6 [OTU55]) or highly connected nodes (Pseudolabrys [OTU14]

\section{TABLE 3}

Results of the permutational multivariate analysis of variance (PERMANOVA) of the $\beta$-diversity of the bacterial community based on Bray-Curtis distances in 2013 and $2014^{z}$

\begin{tabular}{lcccc}
\hline Sources of variation 2013 & df & SS & Pseudo $F$ & $P$ \\
\hline Cultivar & 3 & 0.1455 & 1.122 & 0.281 \\
\hline Location & 2 & 0.4141 & 4.787 & $\mathbf{0 . 0 0 1}$ \\
\hline Time & 1 & 0.1703 & 3.938 & $\mathbf{0 . 0 0 1}$ \\
\hline Cultivar $\times$ location & 6 & 0.1762 & 0.679 & 0.979 \\
\hline Cultivar $\times$ time & 3 & 0.1336 & 1.029 & 0.373 \\
\hline Location $\times$ time & 2 & 0.1576 & 1.822 & $\mathbf{0 . 0 2 9}$ \\
\hline Cultivar $\times$ location $\times$ time & 6 & 0.1923 & 0.741 & 0.935 \\
\hline Residuals & 64 & 2.7683 & & \\
\hline Total & 87 & 4.1580 & & \\
\hline Sources of variation 2014 & & & & \\
\hline Cultivar & 3 & 0.2144 & 1.6176 & 0.066 \\
\hline Location & 2 & 0.2161 & 4.8912 & 0.002 \\
\hline Time & 1 & 1.3840 & 15.6641 & $\mathbf{0 . 0 0 1}$ \\
\hline Cultivar $\times$ location & 6 & 0.1039 & 0.7841 & 0.722 \\
\hline Cultivar $\times$ time & 3 & 0.3041 & 1.1473 & 0.214 \\
\hline Location $\times$ time & 2 & 0.1171 & 1.3251 & 0.166 \\
\hline Cultivar $\times$ location $\times$ time & 6 & 0.1880 & 0.7091 & 0.921 \\
\hline Residuals & 72 & 3.1808 & & \\
\hline Total & 95 & 5.7085 & & \\
\hline 2 Significant results $P<0.05)$ & a & & \\
\hline
\end{tabular}

z Significant results $(P<0.05)$ are indicated in bold. $P$ values were obtained using type III sums of squares (SS) and 999 permutations under the full model. Cultivars: Green Mountain, Agria, Goldrush, and Hindenburg. Time: July and August. Locations: soil close to the plant, rhizosphere soil, and geocaulosphere soils. 
and Acidobacteria subgroup 6 [OTU21]) and other nodes, respectively, were consistent in both 2013 and 2014 (Table 4, Supplementary Fig. S2). Most of the consistent covariances in 2013 and 2014 were positive with seven, two, and nine covariances between Acidobacteria subgroup 6 (OTU55), Pseudolabrys (OTU14), Acidobacteria subgroup 6 (OTU21), and other nodes, respectively. Among these consistent positive covariances, Acidobacteria subgroup 6 (OTU55) and Acidobacteria subgroup 6 (OTU21) had five and three covariances, respectively, with other nodes classified as Acidobacteria subgroup 4 and 6 including a reciprocal covariance between these two OTUs (Table 4, Supplementary Fig. S2).

\section{DISCUSSION}

There is a growing interest in manipulating the soil microbiome to increase plant health and productivity (Chaparro et al. 2012; van Elsas et al. 2012). Common scab of potato causes important economic losses in temperate countries worldwide (Loria et al. 2006); therefore, a better understanding of the possible role of the soil
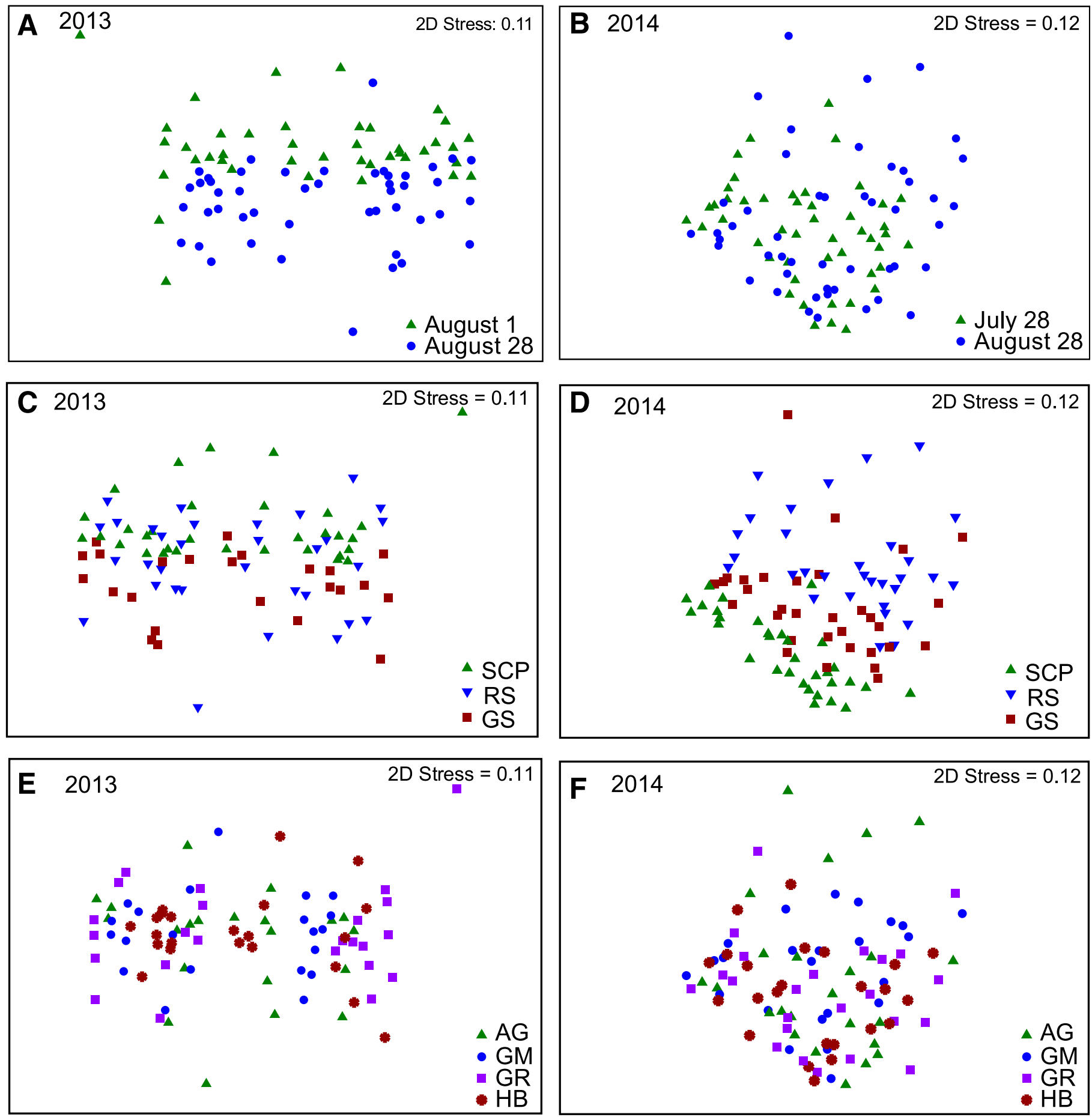

Fig. 5. Nonmetric multidimensional scaling ordination based on Bray-Curtis distances comparing the composition of bacterial communities showing differences between $\mathbf{A}$ and B, sampling dates, C and D, spatial locations (SCP, soil close to the plant; RS, rhizosphere soil; and GS, geocaulosphere soil), and E and F, among cultivars (Agria, AG; Green Mountain, GM; Goldrush, GR; and Hindenburg, HB) in 2013 and 2014. 
microbiome in controlling the abundance of pathogenic Streptomyces spp. may open new avenues to control this disease. Furthermore, it is still unclear how bacterial communities from RS and GS change among potato cultivars and over time. This study evaluated changes in bacterial communities for four cultivars and three spatial locations over two growing seasons.

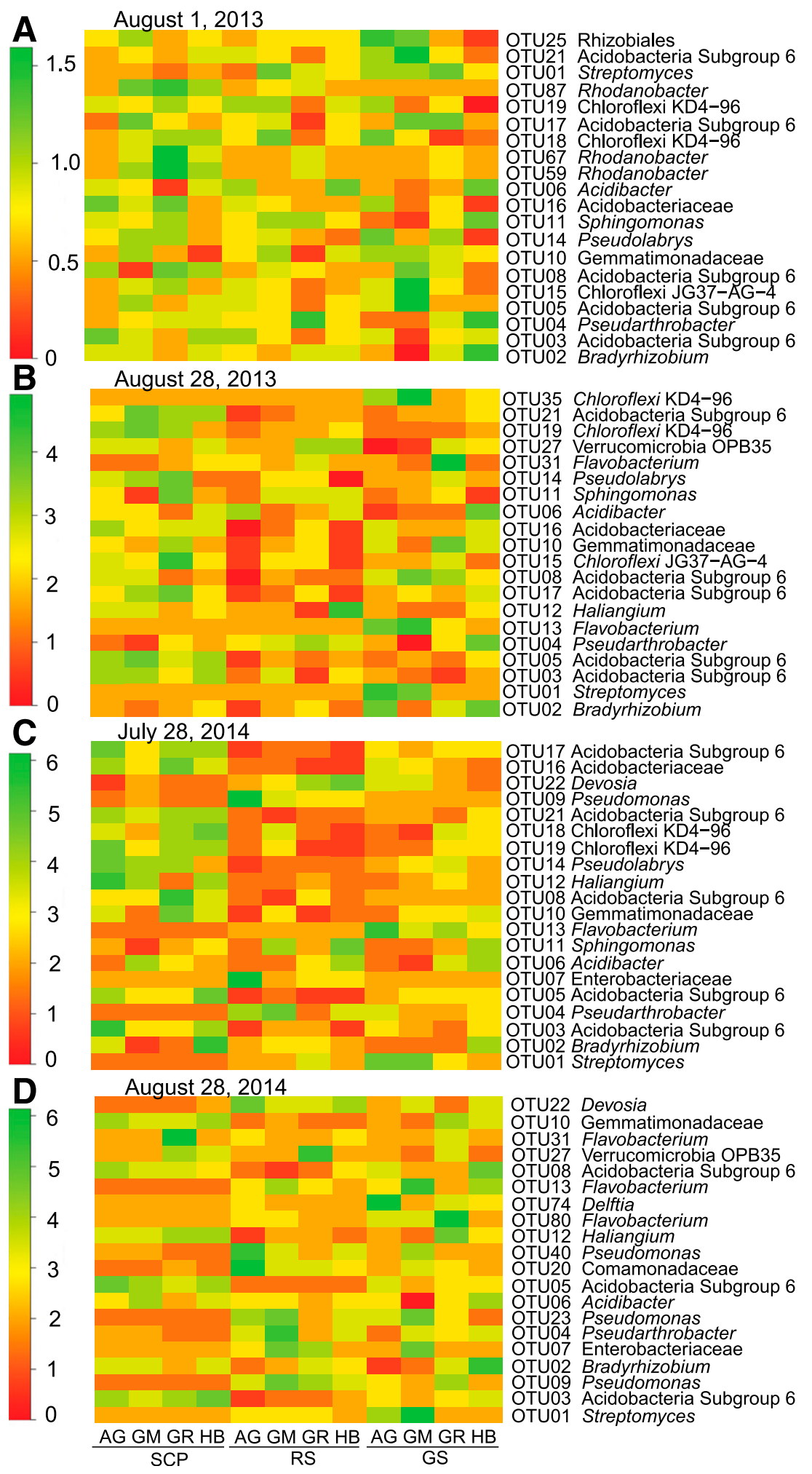

Fig. 6. Heatmap of the 20 most abundant operational taxonomic units (OTUs) for four cultivars (Agria, AG; Green Mountain, GM; Goldrush, GR; and Hindenburg: HB) and three spatial locations (SCP, soil close to the plant; RS, rhizosphere soil; and GS, geocaulosphere soil) for two sampling dates in A and B, 2013 and $\mathbf{C}$ and D, 2014. The 20 most abundant OTUs were selected by averaging the relative abundance over cultivars and spatial locations on each date. The data are presented as individual OTUs. Taxonomic affiliation of each OTU was assigned to the genus level when possible or to the closest known taxonomic level. Taxonomic affiliations are presented in green, yellow, and red indicating high, medium, and low relative abundance, respectively. 
A

2013
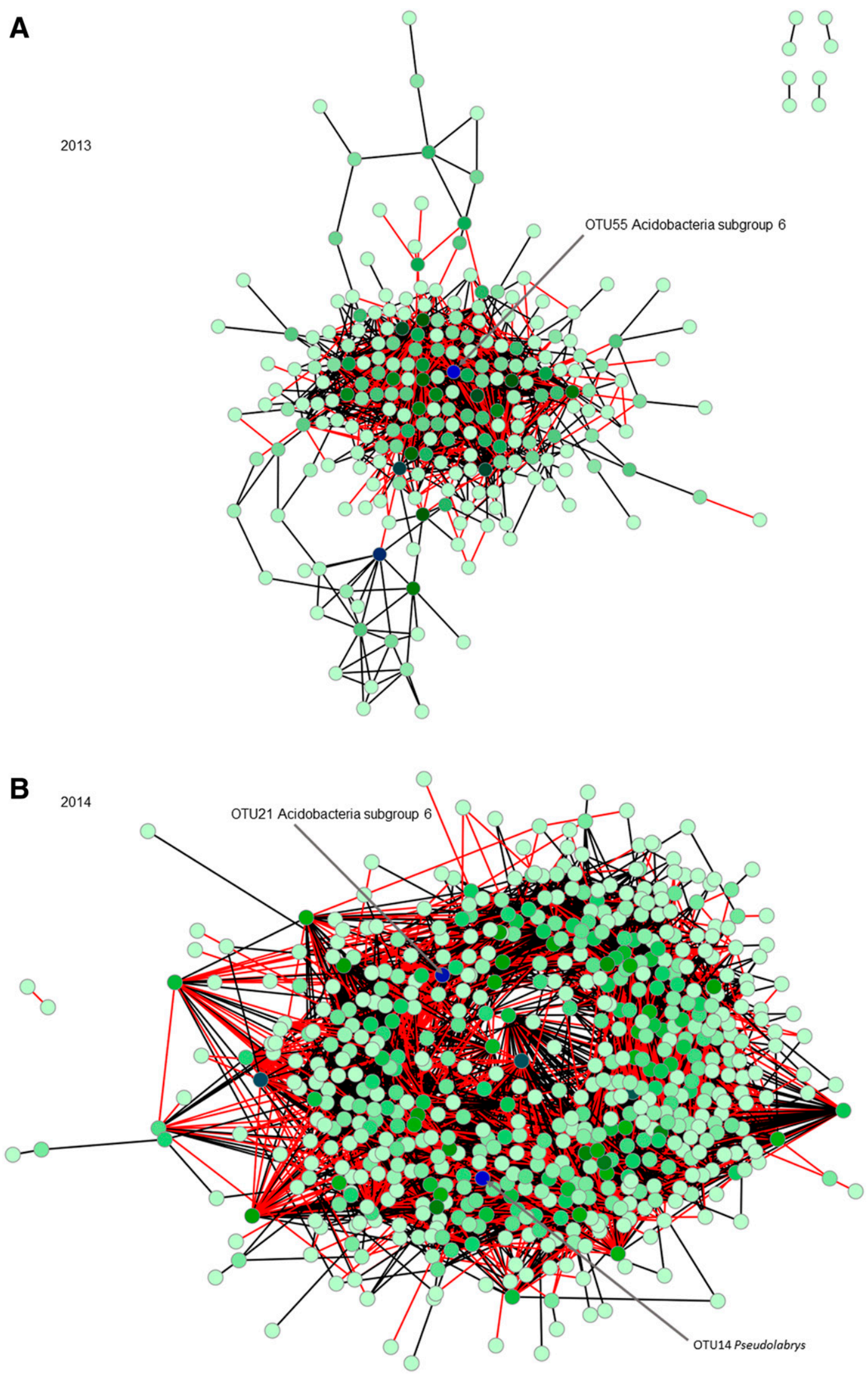

Fig. 7. Network of bacterial co-occurrences in A, 2013 and B, 2014 in the rhizosphere soil for a combination of four potato cultivars. The connections in the network represent significant linkages $(P<0.01)$ between operational taxonomic units as determined by inverse covariance. The color of each node indicates the values of connectivity and network structuration with light green nodes having the lowest values and dark blue having the greatest values. Hub-taxa (2013) and nodes with the greatest number of connections (2014) are indicated with arrows. Positive values of inverse covariance between nodes are presented as black lines while negative values are presented as red lines. 
Effect of potato cultivars on soil bacterial community. Previous studies reported changes in the diversity of the rhizosphere bacterial communities due to differences in plant species and cultivars (Marschner et al. 2001; Berg and Smalla 2009). In contrast, the results of this study showed that in most cases the richness (Chao1) and $\alpha$-diversity of bacterial communities (Shannon index) among cultivars were similar in the RS and GS. However, the bacterial community of Hindenburg had a greater Shannon index compared with Agria on 28 August 2013 and to both susceptible cultivars on 28 August 2014 for RS and to Green Mountain in GS in August 2014. This pattern in the Shannon index was not observed for the SCP, suggesting that the differences in the Shannon index of the bacterial communities between Hindenburg and Agria and/or Green Mountain observed in the RS and GS were not due to spatial heterogeneity of the bacterial community in the field but may be due to differences in the composition and abundance of root exudates. Similarly, differences in the Shannon index of bacterial communities from RS between potato cultivars (Kobayashi et al. 2015) or other plant species were reported (Sun et al. 2013; Wu et al. 2015).

Although some differences in Shannon index were observed among cultivars, there were no significant cultivar-time interactions and cultivar was not a significant factor explaining the $\beta$-diversity of the bacterial community according to PERMANOVA. The discrepancy between the results of the Shannon index and the $\beta$-diversity is not surprising given the few differences observed in Shannon index and richness among cultivars, and that the Shannon index and $\beta$-diversity are two different measurements using different parameters to evaluate the diversity of soil communities. Differences among six potato cultivars were previously reported for an early plant growth stage but not in later stages of growth (flowering and senescence) (İnceoğlu et al. 2011), thus, it is possible that the absence of differences in $\beta$-diversity of bacterial community among cultivars in this study may reflect the time of sampling. Similarly, Weinert et al. (2010) reported that diversity of tuber-associated bacteria (GS and tuber ectodermis) of five commercial cultivars, assessed using PCR-DGGE, were only weakly affected by the plant cultivar. Alternatively, soil physico-properties may have superseded the effect of cultivars. İnceoğlu et al. (2010, 2011) reported more profound effects of soil type compared with potato cultivar on the diversity of bacterial communities in RS using two soil types and six potato cultivars.

Differences in bacterial communities and species between common scab tolerant and susceptible cultivars. The genetic background of potato cultivars influenced the abundance of pathogenic Streptomyces spp. in soils associated with the plant (RS and GS) with a 23 to 46 increase (when averaged over the two sampling dates) in susceptible cultivars compared with tolerant cultivars in 2013 and 2014, respectively, and this trend was also observed on other dates over the sampling period (Nahar et al. 2018). In this study, a possible link between the greater richness, Shannon index, and/or the diversity of soil bacterial communities of common scab tolerant potato cultivars compared with susceptible potato cultivars and the lower abundance of pathogenic Streptomyces spp. was evaluated. There were no clear and consistent differences in Shannon index, richness or $\beta$-diversity of the bacterial communities in RS or GS between common scab susceptible and tolerant cultivars, suggesting that the bacterial communities may not be an important factor influencing the differences in the common scab pathogen abundance between susceptible and resistant cultivars. Similarly, the $\beta$-diversity of bacterial communities from RS at tuberization time was not significantly different among common scab tolerant and susceptible potato cultivars and the $\beta$-diversity of bacterial communities from the GS were not consistently different between susceptible and tolerant cultivars (Kobayashi et al. 2015). Differences in bacterial community diversity for the GS were evaluated using one common scab susceptible and one tolerant potato cultivar during the tuberization period (Kopecky et al. 2018) and close to harvest (Shi et al. 2019). In contrast to the current study

TABLE 4

Consistent covariances between hub-taxa (OTU55) or highly connected nodes (OTU14 and OTU21) and other nodes in both 2013 and 2014

\begin{tabular}{|c|c|c|}
\hline Hub-taxa/highly connected nodes & Positive covariances between $\mathrm{HT} / \mathrm{HCN}^{\mathrm{z}}$ and: & Negative covariances between $\mathrm{HT} / \mathrm{HCN}$ and: \\
\hline Acidobacteria subgroup 6 OTU55 & Acidobacteria subgroup 6 (OTU21) & Massilia (OTU242) \\
\hline Acidobacteria subgroup 6 OTU55 & Blastocatellaceae subgroup 4 (OTU43) & \\
\hline Acidobacteria subgroup 6 OTU55 & Acidobacteria subgroup 6 (OTU118) & \\
\hline Acidobacteria subgroup 6 OTU55 & Acidobacteria subgroup 17 (OTU162) & \\
\hline Pseudolabrys OTU14 & Gemmatimonadaceae OTU10 & Gemmata (OTU204) \\
\hline Pseudolabrys OTU1 & Xanthobacteraceae OTU191 & \\
\hline Acidobacteria subgroup 6 OTU21 & Chloroflexi (OTU19) & Microbacteriaceae (OTU90) \\
\hline Acidobacteria subgroup 6 OTU21 & Chthoniobacterales DA101 (OTU2) & Sphingomonas (OTU153) \\
\hline Acidobacteria subgroup 6 OTU21 & $\beta$-Proteobacteria (OTU54) & \\
\hline Acidobacteria subgroup 6 OTU21 & Acidobacteria subgroup 6 (OTU55) & \\
\hline Acidobacteria subgroup 6 OTU21 & Blastocatellaceae subgroup 4 (OTU112) & \\
\hline Acidobacteria subgroup 6 OTU21 & Acidobacteria subgroup 6 (OTU118) & \\
\hline
\end{tabular}

z HT/HCN, hub-taxa/highly connected nodes. 
and the study of Kobayashi et al. (2015), Kopecky et al. (2018), and Shi et al. (2019) reported that bacterial community of GS differed between the susceptible and tolerant cultivars. The fact that the diversity of bacterial communities between common scab tolerant and susceptible potato cultivars are not consistently different across studies suggests that the negative relationship between the abundance of pathogenic Streptomyces spp. and the diversity of bacterial communities in RG or GS occurs only under specific conditions, i.e., depending on the soil microbial communities present, the potato cultivars, the environmental conditions, and/or the soil physicochemical properties.

Although there were no clear differences in Shannon index or richness between tolerant and susceptible cultivars, the relative abundance of several species in RS and GS were significantly different. In RS, the relative abundances of Acidobacteria subgroup 6 (OTU21) and Devosia (OTU22) were greater in tolerant cultivars compared with susceptible cultivars on 28 August 2013 and 28 July 2014, respectively. The relative abundances of Bradyrhizobium (OTU02) (1 August 2013 and 28 August 2014) and Sphingomonas (OTU11) (1 August 2013 and 28 July 2014) were greater in tolerant cultivars compared with susceptible cultivars in the GS. The differences in relative abundances of the aforementioned OTUs between tolerant and susceptible cultivars may be due to differences in plant growth stage including root architecture and root size (Iwama 2008) and/or in root exudates (Chaparro et al. 2013, 2014; Gschwendtner et al. 2011). Bradyrhizobium, Sphingomonas, and Devosia were previously reported to be involved in disease suppression or suppressive soils (Antoun et al. 1998; Expósito et al. 2017). Although common scab pathogenic Streptomyces spp. growth is favored in susceptible potato cultivars (Nahar et al. 2018), it is possible that the abundance may be partly modulated by specific antagonistic organisms that are more abundant in tolerant cultivars compared with susceptible cultivars, in addition to the tolerance mechanisms of the plant. For example, the percentage of culturable bacteria with an antagonistic effect on the growth of three fungal pathogens varied from 4 to $24 \%$ among seven potato cultivars, demonstrating that the potato cultivar influences the number of interactions between pathogens and antagonistic bacteria (Weinert et al. 2010). Further investigation would be needed to demonstrate if the negative relationships between pathogenic Streptomyces spp. and other OTUs are the result of direct interactions or simply due to opposing influences of other factors, i.e., environmental conditions, out-competition, or predation, on their relative abundances.

Effect of spatial locations on soil bacterial community. $\beta$-diversity of the bacterial community was significantly different among the three spatial locations (SCP, RS, and GS) in both years. It is well documented that diversity of bacterial communities differs between rhizosphere and bulk soils due to the selection by the plant of a subset of bacteria in the rhizosphere (İnceoğlu et al. 2011; Smalla et al. 2001). Clear differences in the bacterial community composition between bulk soil and the RS were demonstrated for six potato cultivars at different growth stages (İnceoğlu et al. 2011) and between RS and GS of eight potato cultivars at tuberization (Kobayashi et al. 2015). The tubers are underground stems and, as such, do not produce exudates thus the geocaulosphere represents a very different habitat when compared with the rhizosphere. The mechanisms that result in selection of a different diversity of the bacterial community in GS compared with RS and SCP are unclear; however, cell death and production of low molecular weight polar and nonpolar metabolites by potato tubers (Dobson et al. 2008) could be involved.

Effect of time on soil bacterial community. $\beta$-diversity of the bacterial community was significantly different between the first and second sampling dates in both years. The plant growth stages, and/or changes in root exudates, could explain the differences in $\beta$-diversity of bacterial community between sampling dates in both years. In late July or early August, the potato plants would have been fully grown and tuber bulking would have started (i.e., plant resources are redirected to the tubers) while in late August, the plants would have been mature with some sign of senescence, and tubers would have still been bulking. Other studies have reported changes in the diversity of bacterial community in the RS of potato over time with a greater difference in diversity of bacterial community at earlier growth stages compared with flowering and senescence (İnceoğlu et al. 2011; Pfeiffer et al. 2017). Alternatively, differences in environmental conditions (atmospheric temperature and rainfall) and soil properties ( $\mathrm{pH}$ and soil $\mathrm{NO}_{3}^{-}$concentrations) could explain the differences in $\beta$-diversity of bacterial community between the sampling dates.

In addition to differences within a given growing season, there were important differences in richness and $\alpha$-diversity of bacterial communities between 2013 and 2014. Greater richness and $\alpha$ diversity of bacterial community were observed in SCP, RS, and GS for 2013 compared with 2014 with the exception of Shannon index of the SCP in 2014. Although richness and bacterial diversity were greater in 2013, the average of the relative abundances of the OTUs was greater in 2014 compared with 2013 . These results could be explained by differences in the environmental conditions (temperature and soil moisture) and soil edaphic properties (inorganic nitrogen concentrations and $\mathrm{pH}$ ) between 2013 and 2014. Previous studies showed that the climatic and soil characteristics, such as soil $\mathrm{pH}$ and soil moisture content, influenced soil bacterial community diversity (İnceoğlu et al. 2013; Jones et al. 2009; Meng et al. 2013).

Temporal effect on soil bacterial networks. The bacterial network analyses showed important differences between the two growing seasons with an increase in the number of mutual exclusion or co-occurrences in the bacterial networks, moving from a relatively simpler bacterial community network in 2013 to a more complex network in 2014. Rainfall averaged over the seven day period prior to each sampling date was greater in 2013 compared with 2014. The increase in the number of potential covariances between bacteria in potato $\mathrm{RS}$ in 2014 , particularly the drastic increase in the number of mutual exclusions, may indicate an intensive competition for resources probably due to the drier conditions in 2014 compared with 2013. In drier soils, nutrient availability likely decreased due to a reduction in diffusion pathways that moves labile compounds between soil particles and microbes (Schimel, 2018). These results suggested changes in ecological functioning and behavior of the bacterial communities of the potato RS between the two growing seasons.

A previous study showed that microbial networks were often modular with clear structuration around nodes (Barberán et al. 2012). In this study, the bacterial networks were not modular but on the contrary were very homogeneous in their structure, suggesting that bacterial communities of potato RS were not mainly driven by the behavior of single taxa but probably by assemblies of taxa thus diminishing the influence of a single taxon on the remainder of the community. Network "hubs" are thought to serve central purposes in their environments such that their loss is believed to cause fragmentation of the whole network (Dunne et al. 2002). One hub-taxa, OTU55, was identified in the bacterial community of 2013 and classified as Acidobacteria subgroup 6. Although none of the nodes in 2014 could be considered hub-taxa, OTU14 and OTU21 showed the highest connectivity with other nodes. OTU21 is also classified as Acidobacteria subgroup 6. Other studies have reported that Acidobacteria subgroup 6 was abundant in potato fields (İnceoğlu et al. 2011) and in common scab suppressive 
soil (Rosenzweig et al. 2012). The dominance of Acidobacteria in soils, with relative abundance ranging from 2.4 to $78.5 \%$ (Janssen 2006; Jones et al. 2009) and their competitiveness (Kielak et al. 2016) may explain why Acidobacteria subgroup 6 is abundant in potato fields and why consistent covariances among Acidobacteria were observed in 2013 and 2014. OTU14 is classified as Pseudolabrys, a genus of the family Xanthobacteraceae and for which only one species has been characterized thus far (Kämpfer et al. 2006). Interestingly, OTU14 and OTU21 were among the 20 most abundant OTUs in this study however OTU55 was not. It is frequently argued that the more abundant taxon often has a greater importance in the network, their abundance being related to betweenness centrality and their connectivity. However, previous studies have reported a few low-abundance taxa that hold central roles in a network and could be considered keystone taxa (Peura et al. 2015). Keystone taxa are defined as having much larger impacts on their community and ecosystem than would be expected from their abundance (Power et al. 1996). Acidobacteria subgroup 6 (OTU55) may be considered a keystone species, given its lower relative abundance.

Although the $\beta$-diversity of bacterial communities did not change among cultivars under the conditions of this study, differences in $\alpha$-diversity and relative abundance of key bacterial taxa were observed among cultivars. This study showed that the differences in the pathogenic Streptomyces spp. abundance between susceptible and tolerant cultivars could not be explained by the differences in bacterial diversity between susceptible and tolerant cultivars. However, it is still possible that antagonistic or synergic interactions between specific taxa and the common scab pathogen may have contributed to differences in the abundance of the common scab pathogen.

\section{ACKNOWLEDGMENTS}

We thank Catherine Clark for invaluable help in planting and harvesting the field trials and in soil sample collection and Karen Terry for the soil analyses.

\section{LITERATURE CITED}

Anderson, M., Gorley, R. N., and Clarke, K. 2008. PERMANOVA+ for primer: Guide to software and statistical methods. PRIMER-E Ltd., Plymouth, U.K.

Antoun, H., Beauchamp, C. J., Goussard, N., Chabot, R., and Lalande, R. 1998. Potential of Rhizobium and Bradyrhizobium species as plant growth promoting rhizobacteria on non-legumes: Effect on radishes (Raphanus sativus L.). Plant Soil 204:57-67.

Barberán, A., Bates, S. T., Casamayor, E. O., and Fierer, N. 2012. Using network analysis to explore co-occurrence patterns in soil microbial communities. ISME J. 6:343-351.

Berg, G., and Smalla, K. 2009. Plant species and soil types cooperatively shape the structure and function of microbial communities in the rhizosphere. FEMS Microbiol. Ecol. 68:1-13.

Bernard, G., Asiedu, S. K., and Boswall, P. (eds.) 1993. Atlantic Canada potato guide. Advisory Committee on Potatoes, Canada.

Chaparro, J. M., Badri, D. V., Bakker, M. G., Sugiyama, A., Manter, D. K., and Vivanco, J. M. 2013. Root exudation of phytochemicals in Arabidopsis follows specific patterns that are developmentally programmed and correlate with soil microbial functions. PLoS One 8:e55731.

Chaparro, J. M., Badri, D. V., and Vivanco, J. M. 2014. Rhizosphere microbiome assemblage is affected by plant development. ISME J. 8: 790-803.

Chaparro, J. M., Sheflin, A. M., Manter, D. K., and Vivanco, J. M. 2012. Manipulating the soil microbiome to increase soil health and plant fertility. Biol. Fertil. Soils 48:489-499.

Dobson, G., Shepherd, T., Verrall, S. R., Conner, D., Mcnicol, J. W., Ramsay, G., Shepherd, L. V., Davies, H. V., and Stewart, D. 2008. Phytochemical diversity in tubers of potato cultivars and landraces using a GC-MS metabolomics approach. J. Agric. Food Chem. 56:10280-10291.
Dunne, J. A., Williams, R. J., and Martinez, N. D. 2002. Network structure and biodiversity loss in food webs: Robustness increases with connectance. Ecol. Lett. 5:558-567.

Edgar, R. C., Haas, B. J., Clemente, J. C., Quince, C., and Knight, R. 2011. UCHIME improves sensitivity and speed of chimera detection. Bioinformatics 27:2194-2200.

Expósito, R. G., De Bruijn, I., Postma, J., and Raaijmakers, J. M. 2017. Current insights into the role of rhizosphere bacteria in disease suppressive soils. Front. Microbiol. 8:2529.

Garbeva, P., Postma, J., van Veen, J. A., and van Elsas, J. D. 2006. Effect of above-ground plant species on soil microbial community structure and its impact on suppression of Rhizoctonia solani AG3. Environ. Microbiol. 8: 233-246.

Griffiths, B. S., Caul, S., Thompson, J., Birch, A. N. E., Cortet, J., Andersen, M. N., and Krogh, P. H. 2007. Microbial and microfaunal community structure in cropping systems with genetically modified plants. Pedobiologia (Jena) 51: $195-206$.

Gschwendtner, S., Esperschutz, J., Buegger, F., Reichmann, M., Muller, M., Munch, J. C., and Schloter, M. 2011. Effects of genetically modified starch metabolism in potato plants on photosynthate fluxes into the rhizosphere and on microbial degraders of root exudates. FEMS Microbiol. Ecol. 76: 564-575.

Gschwendtner, S., Reichmann, M., Müller, M., Radl, V., Munch, J. C., and Schloter, M. 2010. Effects of genetically modified amylopectin-accumulating potato plants on the abundance of beneficial and pathogenic microorganisms in the rhizosphere. Plant Soil 335:413-422.

Hannula, S. E., de Boer, W., and van Veen, J. 2012. A 3-year study reveals that plant growth stage, season and field site affect soil fungal communities while cultivar and GM-trait have minor effects. PLoS One 7:e33819.

İnceoğlu, Ö., Al-Soud, W. A., Salles, J. F., Semenov, A. V., and van Elsas, J. D. 2011. Comparative analysis of bacterial communities in a potato field as determined by pyrosequencing. PLoS One 6:e23321.

İnceoğlu, Ö., Sablayrolles, C., van Elsas, J. D., and Falcão Salles, J. 2013. Shifts in soil bacterial communities associated with the potato rhizosphere in response to aromatic sulfonate amendments. Appl. Soil Ecol. 63:78-87.

İnceoğlu, O., Salles, J. F., van Overbeek, L., and van Elsas, J. D. 2010. Effects of plant genotype and growth stage on the betaproteobacterial communities associated with different potato cultivars in two fields. Appl. Environ. Microbiol. 76:3675-3684.

Iwama, K. 2008. Physiology of the potato: New insights into root system and repercussions for crop management. Potato Res. 51:333-353.

Janssen, P. H. 2006. Identifying the dominant soil bacterial taxa in libraries of 16S rRNA and 16S rRNA genes. Appl. Environ. Microbiol. 72:1719-1728.

Jones, R. T., Robeson, M. S., Lauber, C. L., Hamady, M., Knight, R., and Fierer, N. 2009. A comprehensive survey of soil acidobacterial diversity using pyrosequencing and clone library analyses. ISME J. 3:442-453.

Kämpfer, P., Young, C. C., Arun, A. B., Shen, F. T., Jäckel, U., Mora, R. R., Lai, W., and Rekha, P. D. 2006. Pseudolabrys taiwanensis gen. nov., sp. nov., an alphaproteobacterium isolated from soil. Int. J. Syst. Evol. Microbiol. 56: 2469-2472.

Kielak, A. M., Barreto, C. C., Kowalchuk, G. A., van Veen, J. A., and Kuramae, E. E. 2016. The ecology of Acidobacteria: Moving beyond genes and genomes. Front. Microbiol. 7:744.

Kobayashi, A., Kobayashi, Y. O., Someya, N., and Ikeda, S. 2015. Community analysis of root- and tuber-associated bacteria in field-grown potato plants harboring different resistance levels against common scab. Microbes Environ. 30:301-309.

Kopecky, J., Samkova, Z., Sarikhani, E., Kyselková, M., Omelka, M., Kristufek, V., Divis, J., Grundmann, G. G., Moenne-Loccoz, Y., and SagovaMareckova, M. 2018. The effect of susceptible and resistant potato cultivars on bacterial communities in the tuberosphere of potato in soil suppressive or conducive to common scab disease. bioRxiv 340257.

Kurtz, Z. D., Müller, C. L., Miraldi, E. R., Littman, D. R., Blaser, M. J., and Bonneau, R. A. 2015. Sparse and compositionally robust inference of microbial ecological networks. PLOS Comput. Biol. 11:e1004226.

Kuzyakov, Y., and Blagodatskaya, E. 2015. Microbial hotspots and hot moments in soil: Concept \& review. Soil Biol. Biochem. 83:184-199.

Loria, R., Kers, J., and Joshi, M. 2006. Evolution of plant pathogenicity in Streptomyces. Annu. Rev. Phytopathol. 44:469-487.

Marschner, P., Yang, C. H., Lieberei, R., and Crowley, D. E. 2001. Soil and plant specific effects on bacterial community composition in the rhizosphere. Soil Biol. Biochem. 33:1437-1445.

Meng, H., Li, K., Nie, M., Wan, J. R., Quan, Z. X., Fang, C. M., Chen, J. K., Gu, J. D., and Li, B. 2013. Responses of bacterial and fungal communities to an 
elevation gradient in a subtropical montane forest of China. Appl. Microbiol. Biotechnol. 97:2219-2230.

Miller, M. N., Zebarth, B. J., Dandie, C. E., Burton, D. L., Goyer, C., and Trevors, J. T. 2008. Crop residue influence on denitrification, $\mathrm{N}_{2} \mathrm{O}$ emissions and denitrifier community abundance in soil. Soil Biol. Biochem. 40:2553-2562.

Nahar, K., Goyer, C., Zebarth, B. J., Burton, D. L., and Whitney, S. 2018. Pathogenic Streptomyces spp. abundance affected by potato cultivars. Phytopathol. 108:1046-1055.

Needleman, S. B., and Wunsch, C. D. 1970. A general method applicable to the search for similarities in the amino acid sequence of two proteins. Mol. Biol. J. 48:443-453.

Peura, S., Bertilsson, S., Jones, R. I., and Eiler, A. 2015. Resistant microbial cooccurrence patterns inferred by network topology. Appl. Environ. Microbiol. 81:2090-2097.

Pfeiffer, S., Mitter, B., Oswald, A., Schloter-Hai, B., Schloter, M., Declerck, S., and Sessitsch, A. 2017. Rhizosphere microbiomes of potato cultivated in the High Andes show stable and dynamic core microbiomes with different responses to plant development. FEMS Microbiol. Ecol. 93:fiw242.

Power, M. E., Tilman, D., Estes, J., Menge, B. A., Bond, W. J., Mills, L. S., Daily, G., Castilla, J. C., Lubchenco, J., and Paine, R. T. 1996. Challenges in the quest for keystones. BioSci. 46:609-620.

Quast, C., Pruesse, E., Yilmaz, P., Gerken, J., Schweer, T., Yarza, P., Peplies, J., and Glöckner, F. O. 2013. The SILVA ribosomal RNA gene database project: Improved data processing and web-based tools. Nucleic Acids Res.41: D590-D596.

Raaijmakers, J. M., Paulitz, T. C., Steinberg, C., Alabouvette, C., and MoënneLoccoz, Y. 2009. The rhizosphere: A playground and battlefield for soilborne pathogens and beneficial microorganisms. Plant Soil 321:341-361.

Rasche, F., Hodl, V., Poll, C., Kandeler, E., Gerzabek, M. H., van Elsas, J. D., and Sessitsch, A. 2006. Rhizosphere bacteria affected by transgenic potatoes with antibacterial activities compared with the effects of soil, wild-type potatoes, vegetation stage and pathogen exposure. FEMS Microbiol. Ecol. 56: 219-235.

Rosenzweig, N., Tiedje, J. M., Quensen, J. F., Meng, Q., and Hao, J. J. 2012. Microbial communities associated with potato common scab-suppressive soil determined by pyrosequencing analyses. Plant Dis. 96:718-725.

Schimel, J. P. 2018. Life in dry soils: Effects of drought on soil microbial communities and processes. Annu. Rev. Ecol. Evol. Syst. 49:409-432.

Schloss, P. D., Westcott, S. L., Ryabin, T., Hall, J. R., Hartmann, M., Hollister, E. B., Lesniewski, R. A., Oakley, B. B., Parks, D. H., Robinson, C. J., Sahl, J. W., Stres, B., Thallinger, G. G., Van Horn, D. J., and Weber, C. F. 2009. Introducing mothur: Open-source, platform-independent, communitysupported software for describing and comparing microbial communities. Appl. Environ. Microbiol. 75:7537-7541.

Shi, W., Li, M., Wei, G., Tian, R., Li, C., Wang, B., Lin, R., Shi, C., Chi, X., Zhou, B., and Gao, Z. 2019. The occurrence of potato common scab correlates with the community composition and function of the geocaulosphere soil microbiome. Microbiome 7:14.

Smalla, K., Wieland, G., Buchner, A., Zock, A., Parzy, J., Kaiser, S., Roskot, N., Heuer, H., and Berg, G. 2001. Bulk and rhizosphere soil bacterial communities studied by denaturing gradient gel electrophoresis: Plantdependent enrichment and seasonal shifts revealed. Appl. Environ. Microbiol. 67:4742-4751

Stevenson, W. R., Loria, R., Franc, G. D., and Weingartner, D. P. (eds.) 2001. Compendium of Potato Diseases, 2nd ed. American Phytopathological Society, St. Paul, MN.

Sun, J., Peng, M., Wang, Y., Li, W., and Xia, Q. 2013. The effects of different disease resistant cultivars of banana on rhizosphere microbial communities and enzyme activities. FEMS Microbiol. Lett. 345:121-126.

van der Heijden, M. G. A., Bardgett, R. D., and van Straalen, N. M. 2008. The unseen majority: Soil microbes as drivers of plant diversity and productivity in terrestrial ecosystems. Ecol. Lett. 11:296-310.

van Elsas, J. D., Chiurazzi, M., Mallon, C. A., Elhottova, D., Kristufek, V., and Salles, J. F. 2012. Microbial diversity determines the invasion of soil by a bacterial pathogen. Proc. Natl. Acad. Sci. USA 109:1159-1164.

van Overbeek, L., and van Elsas, J. D. 2008. Effects of plant genotype and growth stage on the structure of bacterial communities associated with potato (Solanum tuberosum L.). FEMS Microbiol. Ecol. 64:283-296.

Verbruggen, E., Roling, W. F., Gamper, H. A., Kowalchuk, G. A., Verhoef, H. A., and van der Heijden, M. G. 2010. Positive effects of organic farming on below-ground mutualists: Large-scale comparison of mycorrhizal fungal communities in agricultural soils. New Phytol. 186:968-979.

Wang, Q., Garrity, G. M., Tiedje, J. M., and Cole, J. R. 2007. Naïve Bayesian classifier for rapid assignment of rRNA sequences into the new bacterial taxonomy. Appl. Environ. Microbiol. 73:5261-5267.

Weinert, N., Meincke, R., Gottwald, C., Heuer, H., Gomes, N. C. M., Schloter, M., Berg, G., and Smalla, K. 2009. Rhizosphere communities of genetically modified zeaxanthin-accumulating potato plants and their parent cultivar differ less than those of different potato cultivars. Appl. Environ. Microbiol. 75:3859-3865.

Weinert, N., Meincke, R., Gottwald, C., Heuer, H., Schloter, M., Berg, G., and Smalla, K. 2010. Bacterial diversity on the surface of potato tubers in soil and the influence of the plant genotype. FEMS Microbiol. Ecol. 74:114-123.

Wu, F. Z., Chen, S. C., Chang, C. L., An, M. J., Zhou, X., and Xu, W. H. 2015. Rhizosphere microbial communities from resistant and susceptible watermelon cultivars showed different response to Fusarium oxysporum f. sp. niveum inoculation. Pak. J. Bot. 47:1535-1546.

Yang, C. H., Crowley, D. E., Borneman, J., and Keen, N. T. 2001. Microbial phyllosphere populations are more complex than previously realized. Proc. Natl. Acad. Sci. USA 98:3889-3894.

Yang, Y., Wang, N., Guo, X., Zhang, Y., and Ye, B. 2017. Comparative analysis of bacterial community structure in the rhizosphere of maize by highthroughput pyrosequencing. PLoS One 12:e0178425.

Yilmaz, P., Parfrey, L. W., Yarza, P., Gerken, J., Pruesse, E., Quast, C., Schweer, T., Peplies, J., Ludwig, W., and Glockner, F. O. 2014. The SILVA and "Allspecies Living Tree Project (LTP)" taxonomic frameworks. Nucleic Acids Res.42:D643-D648.

Zhang, W. W., Lu, Z. T., Yang, K., and Zhu, J. J. 2017. Impacts of conversion from secondary forests to larch plantations on the structure and function of microbial communities. Appl. Soil Ecol. 111:73-83. 